\title{
Modeling the Strength Degradation and Fatigue of Carbon Fiber Rein- forced Composites
}

\author{
Pasquale Verde \\ The Second University of Naples - SUN Department of Aerospace and Mechanical Engineering Via Roma 19 Aversa \\ (CE) 81031, Italy
}

\begin{abstract}
Static and fatigue data available in literature concerning carbon fiber reinforced composite laminates subjected tension-tension fatigue were re-elaborated in the framework of a two-parameter fatigue model explicitly accounting for the cyclic as well as the mean stress. The data were used to obtain the model parameters by best fitting procedures. A primitive statistical implementation of the model was based on the hypothesis that the monotonic tensile strength follows a two-parameter Weibull distribution. The model has the potential of being predictive indicating that the fatigue characterization of given laminate can be achieved with a minimum of experimental tests. The model reliability and its applicability limits are discussed.
\end{abstract}

Keywords: Fatigue, carbon fibers, composites, residual strength, Weibull distribution.

\section{INTRODUCTION}

Carbon fiber reinforced polymer based composites have emerged as superior engineering materials due to attributes that are not attainable with existing engineering materials. Due to these advantages, composite laminates provide an opportunity for cost-efficient high performance in many weight-critical applications in spite of a product cost impediment compared with traditional materials. However composites are multiphase and anisotropic materials requiring higher sampling for their characterization, compared to metals. This aspect is very much highlighted when the fatigue behavior is under concern, considering the statistical nature of the phenomenon. In fact, the fatigue behavior of composites is very peculiar, resulting in the accumulation of diffuse damage having different origin and location, rather than the propagation of a single crack as in metals. Fiber fracture, matrix cracking, matrix crazing, fiber buckling, fiber-matrix interface failure and delamination are interacting sources of failures showing different growth rates [1-8]. Further the fatigue lifetime of composite materials is influenced primarily from the matrix and fibers type, the geometry of reinforcement (unidirectional, mat, fabric, braiding), the laminate stacking sequence, the environmental conditions (mainly temperature and moisture), the loading history (stress ratio, $\mathrm{R}$, cyclic frequency..) and boundary conditions. One more subtle phenomenon influencing fatigue is the viscoelastic nature of the matrix that accumulates residual stresses depending on the manufacturing process characteristics. Furthermore it was shown that the structural relaxation of the in situ resin (i.e. the resin constrained into the fibers lattice)

\footnotetext{
*Address correspondence to this author at The Second University of Naples -SUN Department of Aerospace and Mechanical Engineering Via Roma 19 Aversa (CE) 81031, Italy; Tel: 390815010291; Fax: +390815010291;

E-mail: pasquale.verde@unina2.it
}

may influence its nominal glass transition [9-15]. Samples conditioned in the vicinity of $\mathrm{Tg}$ showed higher characteristic strength, which resulted in a correspondingly higher fatigue life compared to the as manufactured materials. All the above phenomena would be preferably included in a fatigue damage modeling. However, this task is really difficult and expensive. The first reason are the several scales where damage mechanisms are present. Secondly, it is impossible reproducing perfectly identical specimens for fatigue as well as static characterization. In turn, the different micro-structural specimens features claims for a statistical approach that requires time-consuming testing procedures.

On the other hand many models have been established for laminates with a particular stacking sequence, under given loading conditions. Thus, all the above considerations explain why the extrapolation to real structures is almost impossible, owing to the fact that the stacking sequence may be a variable and the "in service" loading history is much more complex than that used in a laboratory environment. Commonly the cyclic fatigue data are termed S-N data and are presented as the maximum cyclic stress, $S_{\max }$, or the normalized maximum stress, $S_{\max } / S_{0}$, ( $S_{0}$ being the static material strength) or stress amplitude, $S_{\max }-S_{\min }$, as a function of number of cycles to failure, $N$. The fatigue data are obtained at a fixed value of the maximum stress and the stress ratio, $\mathrm{R}=S_{\min } / S_{\max }$, the latter parameter representing the severity of loading conditions. However, it is a matter of fact that, given $S_{\max }$, higher stress ratio, $R$, imply higher cycles to failure, thus the phenomenological analytic models appeared in literature assume $\mathrm{R}$ as the main variable [5]. The complexity of factors influencing fatigue and their eventual interaction explain why one of the most intricate tasks in designing with composite laminates is the definition of reliable allowable strength. This is partly due also to the usually large scatter in mechanical properties, strongly affected by the fabrication 
methods utilized. For example substantial residual stresses arise in the polymer matrix that act as non-mechanical loads and influence the strength of the composites [11-16]. However, another drawback comes from the difficulty to predict the long-term behavior of the material after exposure to adverse conditions, e.g. aggressive environments, near glass transition, Tg, service temperature or cyclic loadings [1526]. In particular in the vicinity of the glass transition temperature of the polymer matrix the structural relaxation alters the viscoelastic behavior of the matrix itself and affects its long-term behavior [27-36]

This complicates the modeling of composites response to fatigue, which in addition to the material structure is also strongly dependent on external factors such as maximum applied stress, stress ratio, frequency and stress history.

The loading frequency is strictly related to temperature problems arising from hysteretic heating. In fact, for most thermoplastic and thermoset systems the temperature rise on the surface of the specimen should be monitored in exploratory tests and should not exceed a few degrees Celsius, which is usually unavoidable. No standard frequency is universally recognized. However, values between one and ten Hertz are typically selected to ensure against hysteretic heating. Further, in [3-5-7-13] the loading frequency was adjusted as function of maximum stress amplitude to give a quasiconstant loading rate.

In all a reliable and cost-effective fatigue life prediction methodology requires a physically based modeling of fatigue damage evolution. A major obstacle to developing mechanistic models for composites is the complexity of the fatigue damage mechanisms. Overcoming this obstacle requires insightful simplifications that would allow the use of well established mechanics modeling tools possibly without compromising the essential physical nature of the fatigue process. On the other side, the phenomenological fatigue life models extract information from the $\mathrm{S}-\mathrm{N}$ curves and possibly propose a fatigue failure criterion. Thus, they do not take into account damage accumulation, but predict the number of cycles at which fatigue failure occurs under fixed loading conditions. Along this line in previous work, D'Amore et al [3] hypothesized that the residual strength undergoes a continuous decay, following a power law, for their damage law. The strength decay was essentially attributed to the cyclic stress. However, based on tests carried out adopting different stress ratio, $\mathrm{R}$, it was observed that for many composites the fatigue life decreased sharply with decreasing stress ratio. This behavior was interpreted in terms of mean stress, $\sigma_{\text {mean }}=\left(\sigma_{\max } \sigma_{\min }\right) / 2$, and stress amplitude, $\Delta \sigma=\left(\sigma_{\max }-\sigma_{\min }\right) / 2$ even if at high stress the lifetime of several glass reinforced composites was apparently affected by the stress amplitude alone.

As already specified, the nature of the methods adopted in [3, 4, and 5] is essentially empirical, because it relies on experimental observations only. Therefore, no information is gathered on the causes of fatigue damage development. At this point, it seems likely, therefore, that a single fatigue model is unlikely to attain general validity, so that it becomes important to define the limits of applicability of the various methods available in literature. In this respect, this paper presents a re-elaboration of static and fatigue data available in literature $[37,38]$ concerning carbon fiber rein- forced laminates. The data were used to obtain the parameters of a recent model [3] accounting for both mean stress and stress amplitude. The model reliability is discussed highlighting the limits of its applicability.

\section{ANALYTICAL BACKGROUND}

In D'amore et al [3] a two parameter model was proposed for the prediction of the fatigue lifetime of Random Glass Fiber Reinforced Plastics [RGFRP]. The starting point of the model is the hypothesis that the material strength undergoes a continuous decrease with fatigue cycle evolution, according to the power law:

$\frac{d \sigma_{n}}{d n}=-\left[\alpha \Delta \sigma-(1-\alpha) \sigma_{\text {mean }}\right] n^{-b}$

where $\sigma_{\mathrm{n}}$ is the residual material strength after $n$ cycles, $\alpha$ and $b$ are positive constants and $\Delta \sigma=\left(\sigma_{\max }-\sigma_{\min }\right) / 2$, and $\sigma_{\text {mean }}=\left(\sigma_{\max }+\sigma_{\min }\right) / 2$ are the cyclic and the mean stresses, respectively. $\alpha(0<\alpha<1)$ is the parameter partitioning the fatigue sensitivity to cyclic and mean stress. Expressing the cyclic and the mean stress as function of the stress ratio $\mathrm{R}=\sigma_{\min } / \sigma_{\max }$, by integration of equation 1 and using the boundary condition $n=1 \rightarrow \sigma_{n=} \sigma_{0}$, where $\sigma_{0}$ is the strength of the virgin material, the following relationship was obtained:

$\sigma_{0}-\sigma_{n}=\sigma_{\max }\left(\frac{\alpha(1-R)-(1-\alpha)(1+R)}{2 \beta}\right)\left(n^{\beta}-1\right)$

According to equation 2, the evolution of strength degradation with fatigue cycling can be calculated, provided the constants $\alpha$ and $\beta$ (with $\beta=1-b$ ), only dependent on the material and loading conditions, are known. Of course, it is natural to think that the failure will happen when the residual strength equals the maximum applied stress during fatigue, so that the critical number of cycles for failure, $\mathrm{N}$, can be calculated putting $\sigma_{\mathrm{n}=} \sigma_{\max }$ in equation 2. Solving for N, we obtain:

$N=\left[\left(\frac{\sigma_{0}}{\sigma_{\max }}-1\right) \frac{2 \beta}{\alpha(1-R)-(1-\alpha)(1+R)}+1\right]^{1 / \beta}$

Equation (5) can be rearranged to obtain

$\left(\frac{\sigma_{0}}{\sigma_{\max }}-1\right)\left[\frac{2 \beta}{\alpha(1-R)-(1-\alpha)(1+R)}\right]=N^{\beta}-1$

from which the parameters $\alpha$ and $\beta$ are obtained by best fitting procedure from fatigue data usually expressed in terms of $\sigma_{\max } / \sigma_{0}$ vs. number of cycles to failure, $\mathrm{N}$, at given stress ratio, $\mathrm{R}$.

Moreover, when equation 4 is solved for $\sigma_{0}$ one obtains:

$\sigma_{0}=\sigma_{0 N}=\sigma_{\max }\left[\left(N^{\beta}-1\right) \frac{\alpha(1-R)-(1-\alpha)(1+R)}{2 \beta}+1\right]$

From a physical viewpoint equation 5 indicates that the ultimate strength of the virgin material can be calculated from the fatigue life, $N$. The symbol $\sigma_{0 N}$ has been used in equation 8 just to distinguish the calculated strength from that, $\sigma_{0}$, directly measured in a static characterization test.

\section{MODEL RELIABILITY}

In References [3-5] the model reliability was proved describing the classical S-N curves for both glass reinforced thermoplastic and thermosetting matrices. However, the mechanisms of damage accumulations and failure in glass 
reinforced plastics are different from those observed in graphite/epoxy laminates, where matrix splitting accumulation and delamination play an important role in determining the final collapse. Therefore the reliability of our approach has still to be assessed for carbon fiber laminates. To do that, in this paper, the scheme already adopted in reference [9] will be followed. The experimental data are taken from reference [37], where both monotonic and fatigue tests were carried out on T300/934 graphite/epoxy laminates with $\left[0 / 45 / 90-45_{2} / 90 / 45 / 0\right]_{2}$ lay-up.

The static strength data are presented in Fig. (1) where the characteristic strength, $\sigma_{0}=479.6 \mathrm{MPa}$, and the shape parameter, $\gamma=24.4$, of the two-parameter Weibull distribution are evaluated by best fitting procedures. In Reference [37], tension-tension test were also performed with $\mathrm{R}=0$, using three different levels for $\sigma_{\max }$, namely: $\sigma_{\max }=400 \mathrm{MPa}, \sigma_{\max }=$ $345 \mathrm{MPa}$ and $\sigma_{\max }=290 \mathrm{MPa}$ and the results are summarized in Table 1.

The data are then re-elaborated on the basis of our approach by means of equation 4 and reported in Fig. (2) where , by best fitting, the parameters $\alpha$ and $\beta$ can be obtained.

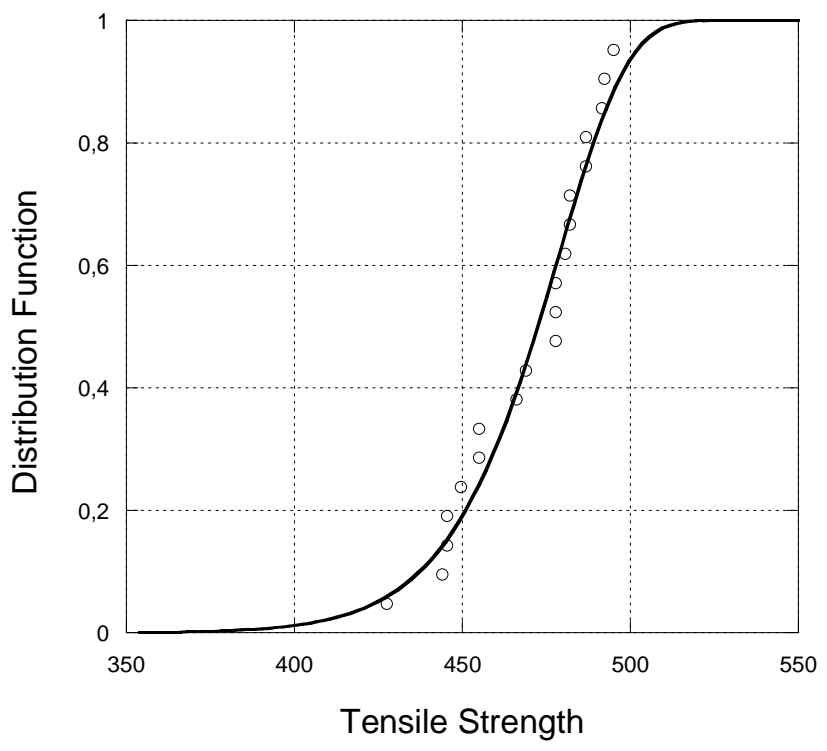

Fig. (1). Statistical distribution of the measured monotonic strength, бo, for T300/934 graphite/epoxy laminates with [0/45/90$\left.45_{2} / 90 / 45 / 0\right]_{2}$ lay-up. Experimental data taken from reference [37].

Table 1. Fatigue Results for T300/934 Graphite/Epoxy Laminates with [0/45/90-45/90/45/0 $]_{2}$ lay-up [34]. Stress Ratio R=0.

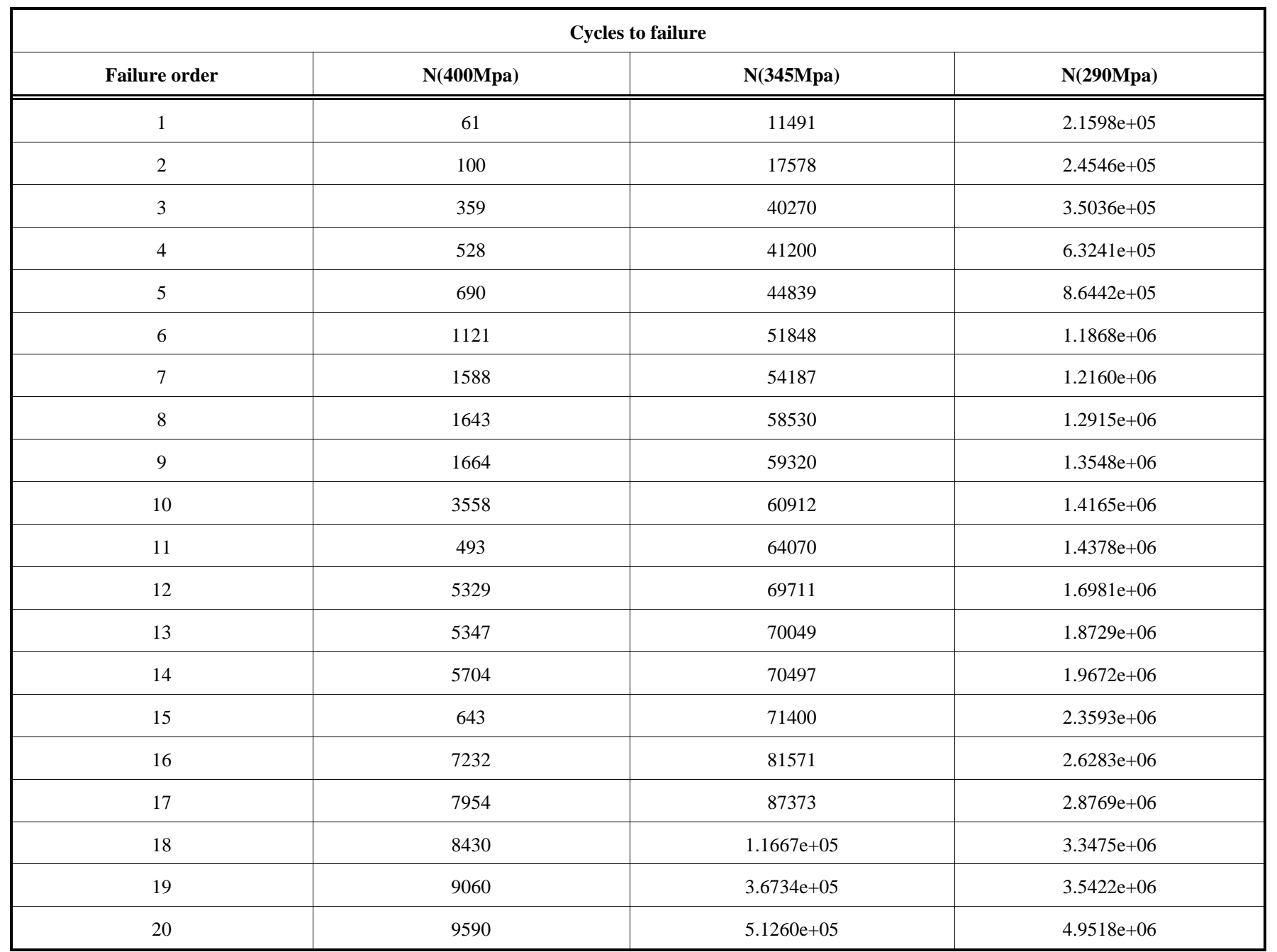




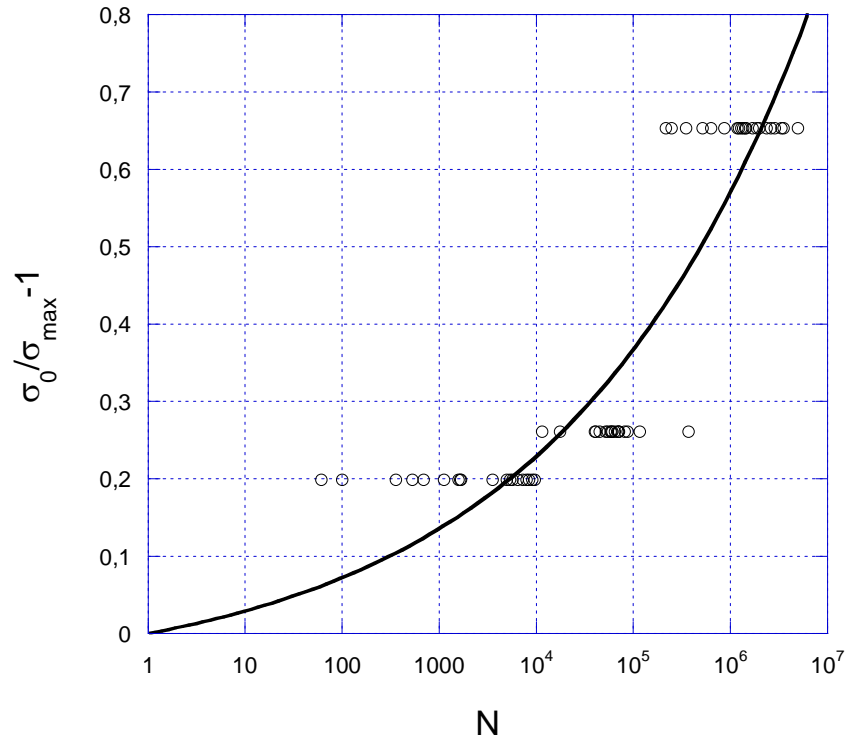

Fig. (2). Re-elaboration of data reported in Table $\mathbf{1}$ according to equation 6

A useful way to test the model reliability consists of its potential ability to predict the monotonic strength from fatigue data as described by equation 5 .

It assumed that the scatter in the monotonic material strength, $\sigma_{0}$, is well represented by a two-parameter Weibull distribution. Therefore the probability of finding a $\sigma_{0}$ value $\leq \mathrm{x}$ is given by:

$F_{\sigma_{0}}(x)=P\left(\sigma_{0} \leq \mathrm{x}\right)=1-\exp \left[-(\mathrm{x} / \gamma)^{\delta}\right]$

where $\gamma$ is the scale parameter or the characteristic strength, and $\delta$ is the shape parameter. Accordingly, in Fig. (3) the static strength and the theoretical static strength, $\sigma_{0 \mathrm{~N}}$, coming out from our analytical model expressed by equation 5 and resulting from fatigue data, are reported. A reasonable agreement between the two statistical distributions can be recognized. Some small observable discrepancies between the Weibull parameters, (namely, the characteristic strength and the shape parameter) are attributed to the different sampling of experimental static strength data, $\sigma_{0}$, and the calculated monotonic strength, $\sigma_{0 \mathrm{~N}}$, spurted from fatigue data according to equation 5 .

It appears that the scatter in fatigue life is uniquely due to the variability in monotonic strength according to the strength-life equal rank assumption [10, 11].

Based on the above assumption the modeling approach can be further implemented statistically. In fact, according to equations 5 and 6 , it can be easily recognized that the relationship allowing for the calculation of the probability $\mathrm{F}\left(\mathrm{N}^{*}\right)$ to find an $\mathrm{N}$ lower that $\mathrm{N}^{*}$ can be written as follows:

$\boldsymbol{F}_{\boldsymbol{N}}\left(\boldsymbol{N}^{*}\right)=\mathbf{1}-\boldsymbol{e x p}\left\{-\frac{\boldsymbol{\sigma}_{\max }^{\delta}\left[\left(N^{* \beta}-1\right) \frac{\alpha(1-R)-(1-\alpha)(1+R)}{2 \beta}+1\right]^{\delta}}{\gamma^{\delta}}\right\}$

Where the parameters $\alpha, \beta, \gamma$ and $\delta$ have been already defined.

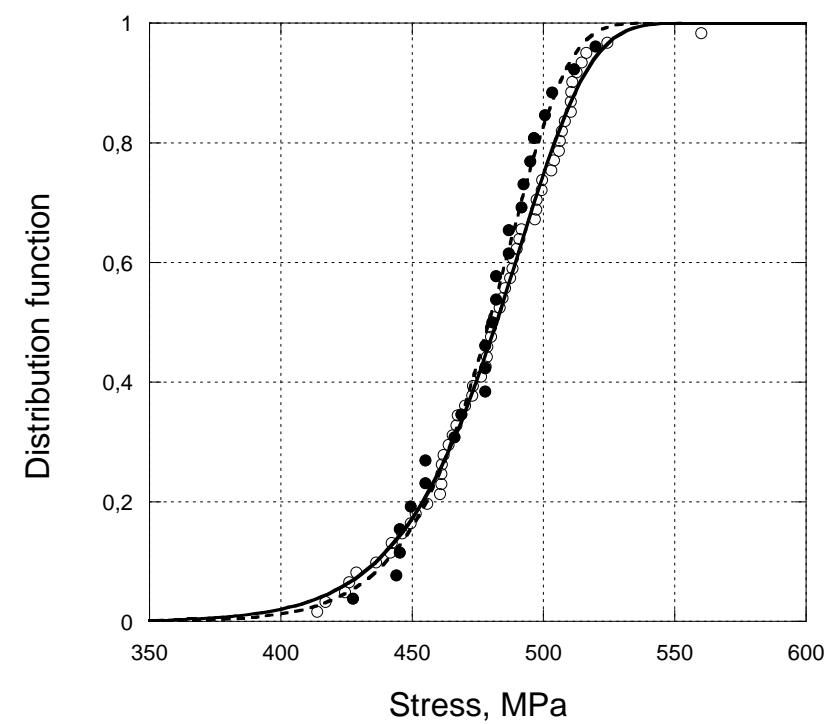

Fig. (3). Statistical distribution of static strength $\sigma_{\mathrm{o}}$ (filled symbol) and the calculated (according to equation 8) monotonic strength, $\sigma_{\text {on }}$, for T300/934 graphite/epoxy laminates with [0/45/90$\left.45_{2} / 90 / 45 / 0\right]_{2}$ lay-up. Experimental data taken from reference [37].

According to equation 7 in Figs $(\mathbf{4}, \mathbf{5}$ and $\mathbf{6})$ the probability of failure as function of cycles number is reported for the three maximum stresses, namely: $\sigma_{\max }=400 \mathrm{MPa}$, $\sigma_{\max }=345 \mathrm{MPa}$ and $\sigma_{\max }=290 \mathrm{MPa}$. Some small discrepancy between the experimental data (symbols) and the model prediction (continuous line) can be observed in Fig. (5), while Fig. (4 and 6) shows a reasonable agreement between experiments and model predictions.

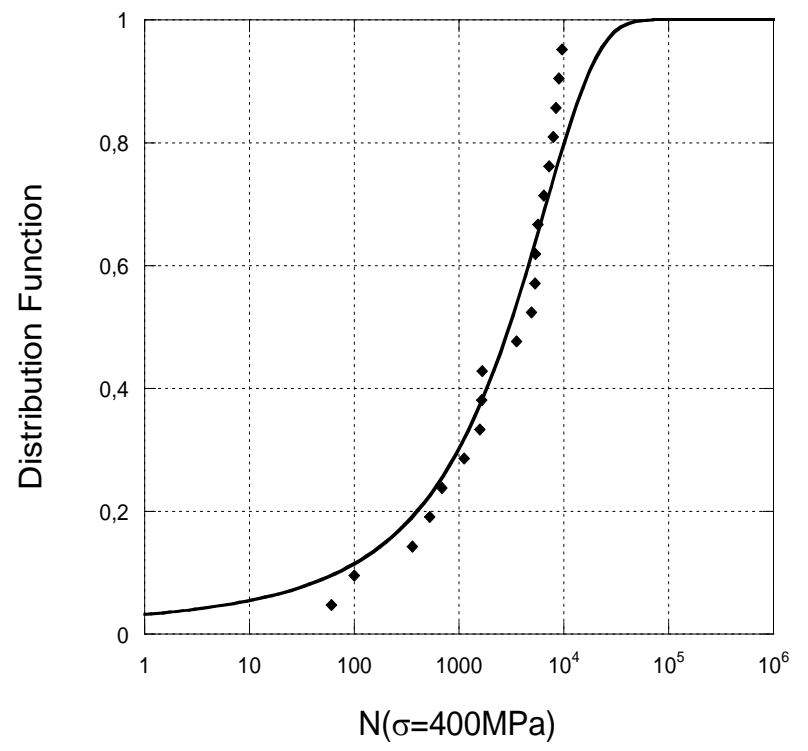

Fig. (4). Probability of failure of fatigue data for T300/934 graphite/epoxy laminates with [0/45/90-45 $/ 90 / 45 / 0]_{2}$ lay-up. Maximum applied stress $\sigma=400 \mathrm{MPa}$. Experimental data taken from reference [37].

The reason the model doesn't capture the principal features of the fatigue data at the intermediate stress, namely when $\sigma_{\max }=345 \mathrm{MPa}$ is not understood, actually. However 
the same discrepancies have been observed by different authors $[9,37]$ on the same data set, even using different models. Again, concerning the data taken at $\sigma_{\max }=400 \mathrm{MPa}$ and $\sigma_{\max }=290 \mathrm{MPa}$, the present approach yields similar response compared to the data elaborated in references [9, 37], with negligible discrepancies. To this end, equation 2 is an empirical expression. However it has the potential to describe both the fatigue life and the scatter in tension-tension fatigue of composite laminates.

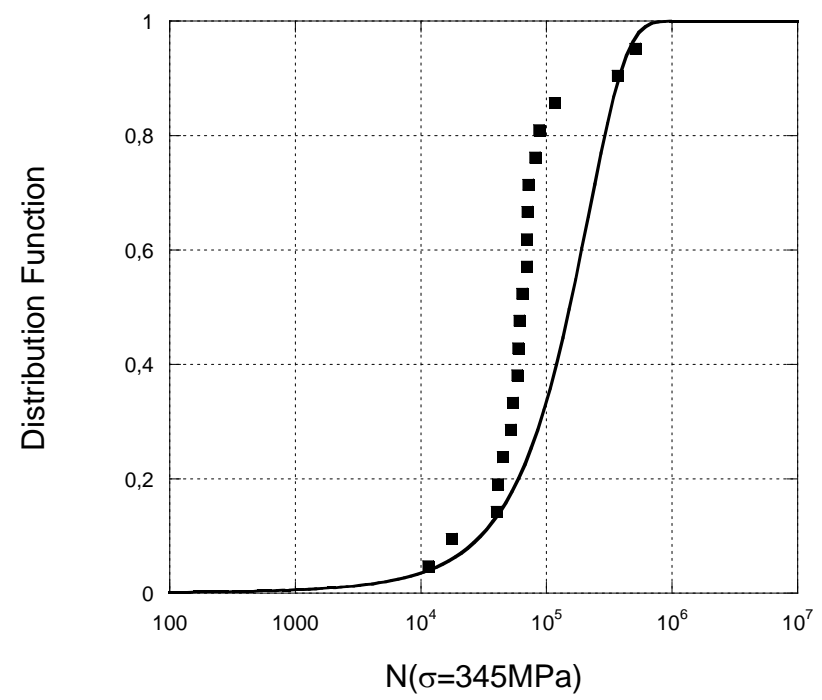

Fig. (5). Probability of failure of fatigue data for T300/934 graphite/epoxy laminates with [0/45/90-45 $2 / 90 / 45 / 0]_{2}$ lay-up. Maximum applied stress $\sigma=345 \mathrm{MPa}$. Experimental data taken from reference [37].

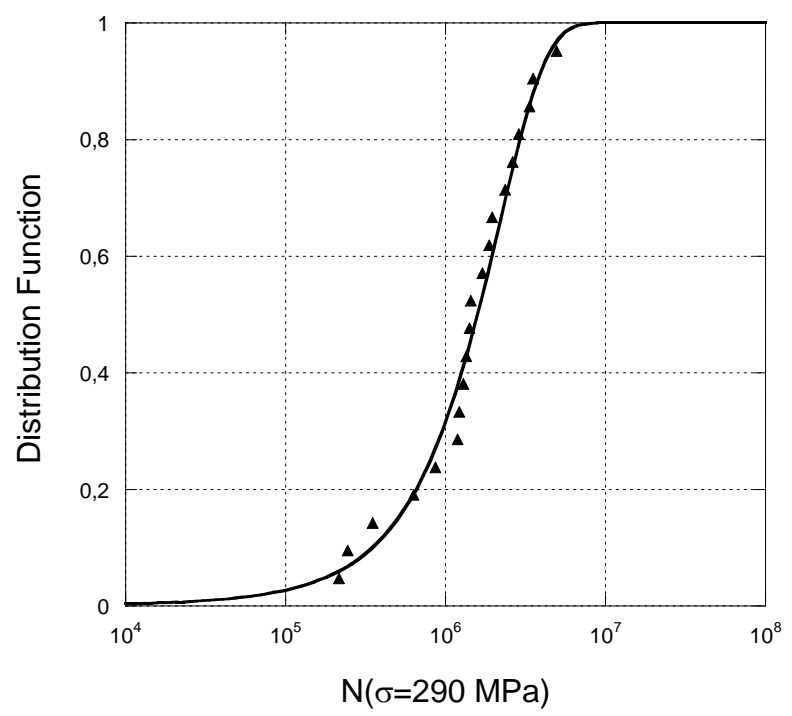

Fig. (6). Probability of failure of fatigue data for T300/934 graphite/epoxy laminates with $\left[0 / 45 / 90-45_{2} / 90 / 45 / 0\right]_{2}$ lay-up. Maximum applied stress $\sigma=290 \mathrm{MPa}$. Experimental data taken from reference [37].

\section{CONCLUSIONS}

A fatigue model explicitly accounting for the cyclic as well as the mean stress was tested on the basis of static and fatigue data for a graphite/epoxy laminate. The model confirms the strength-life equal rank assumption and predicts reasonably the probability of failure under cyclic loading. The model has the potential of being statistically implemented assuming a distribution of static strength according to a two-parameter Weibull distribution. However the phenomenological nature of the model limits its applicability when the parameters governing the fatigue life are modified. For example we are confident the model requires some modifications when the loading mode change from tension-tension to tension-compression. Of course, the laminate stacking sequence dictate also the evolution of fatigue damage and the strength degradation kinetics, given the loading history, so that generalizing the model to different stacking sequences appears rather difficult if not impossible. On the other side, moving to a generalized model taking into account simultaneously the parameters that influence the fatigue performance of composites (namely, fiber type, matrix type, the reinforcement structure, laminate stacking sequence, environmental conditions and boundary condition) would be very useful but may require oversimplifications. We restrict our future work trying to extend the phenomenological approach for uniaxial constant amplitude loading to more general loading condition, such as block type and spectrum loading and to take into account the effect of cyclic frequency and multiaxial loads.

\section{CONFLICT OF INTEREST}

The authors confirm that this article content has no conflicts of interest.

\section{ACKNOWLEDGEMENTS}

None declared.

\section{REFERENCES}

[1] Mandell JF. Fatigue behavior of short fiber composite materials. In: Reifsnaider KL, Ed. Fatigue of Composite Materials. New York: Elsevier Publ 1990; pp. 231-7.

[2] Hour KY, Sehitoglu H. Proof testing of composite materials. J Comp Mater 1993; 27: 782-805.

[3] D'Amore A, Caprino G, Stupak P, Zhou J, Nicolais L. Effect of stress ratio on the flexural fatigue behaviour of continuous strand mat reinforced plastics. Sci Eng Compos Mater 1996; 5: 1-8.

[4] D'Amore A, Grassia L, Verde P. Modeling the Flexural Fatigue Behavior of Glass Fiber Reinforced Thermoplastic Matrices. Mech Time-Depend Mater 2012; DOI: 10.1007/s11043-012-9192-y

[5] D'Amore A, Grassia L, Verde P. Modeling the Fatigue Behavior of Glass Fiber Reinforced Thermoplastic and Thermosetting Matrices. AIP Conf Proc 2012; Ischia Italy; vol. 1459: pp. 372-4.

[6] Fawaz Z, Ellin F. Fatigue failure model for fibre - reinforced materials under general loading conditions. J Compos Mater 1994 28(15): 1432-51

[7] Caprino G, D'Amore A. Flexural fatigue behaviour of randomcontinous-fibre-reinforced thermoplastic composites. Comp Sci Technol 1998; 58(6): 957-65.

[8] Caprino G. Predicting fatigue life of composite laminates subjected to tension-tension fatigue. J Compos Mater 2000; 34(16): 1334-55.

[9] Hahn HT, Kim RY. Proof testing of composite materials. J Compos Mater 1975; 9: 297-311.

[10] Chou PC, Croman R. Residual Strength in Fatigue Based on Strength-life equal rank assumption. J Compos Mater 1978; 12: 177-94.

[11] D'Amore A, Caputo F, Grassia L, Zarrelli M. numerical evaluation of structural relaxation-induced stresses in amorphous polymers. Compos A Appl Sci Manuf 2006; 37: 556-64.

[12] Grassia L, D’Amore A. Residual stresses in amorphous polymers. Macromol Symp 2005; 228: 1-15. 
[13] Zarrelli M, Partridge IK, D'Amore A. Warpage induced in bimaterial specimens: Coefficient of thermal expansion, chemical shrinkage and viscoelastic modulus evolution during cure. Compos A Appl Sci Manuf 2006; 37: 565-57

[14] Grassia L, D'Amore A. Calculation of the shrinkage induced residual stress in a viscoelastic dental restorative material. Mech Time Depend Mater, DOI: 10.1007/s11043-012-9190-0.

[15] Grassia L, D'Amore A. Modeling the residual stresses in reactive resins-based materials: a case study of photo-sensitive composites for dental applications. AIP Conf Proc 2010; 1255: 408-10.

[16] Grassia L, Pastore C MG, D'Amore A. Modeling of the isobaric and isothermal glass transitions of polystyrene. J Appl Polym Sci 2011; 122: 3752-7

[17] D'Amore A, Grassia L, Acierno D. Modelling the yield stress and the Poisson's ratio of glassy polymers. E-Polymers 2009; art no 052 .

[18] Grassia L, D'Amore A, Verde P. On The Inter-Conversion Between Viscoelastic Material Functions of Polycarbonate. AIP Conf Proc 1459; 2012: 375-7.

[19] Grassia L, D'Amore A. Thermal residual stresses in amorphous thermoplastic polymers. AIP Conf Proc 2010; 1255: 414-6.

[20] Grassia L, D'Amore A. Finite element calculation of residual stress in dental restorative material. AIP Conf Proc 2012; 1459: 312-5.

[21] Martone A, Grassia L, Zarrelli M, Giordano M, D'Amore A. Enthalpy relaxation of an epoxy matrix/carbon nanotubes. AIP Conf Proc 2012; 1459: 347-9.

[22] Alfani R, Colombet P, D'Amore A, Rizzo N, Nicolais L. Effect of temperature on thermo-mechanical properties of Macro-DefectFree cement-polymer composite. J Mater Sci 1999; 34: 5683-7.

[23] D'Amore A, Caprino G, Nicolais L, Marino G. Long-term behaviour of PEI and PEI-based composites subjected to physical aging. Compos Sci Technol 1999; 59: 1993-2003.

[24] Caprino G, D'Amore A, Facciolo F. Fatigue sensitivity of random glass fibre reinforced plastics. J Compos Mater 1998; 32(12): 120320.
[25] Netti P, D'Amore A, Ronca D, Ambrosio L, Nicolais L, Structuremechanical properties relationship of natural tendons and ligaments. J Mater Sci Mater Med 1996; 7: 525-30.

[26] Anderson J, Korsgaard. International conference on fatigue of composites: Proceedings 3-5 June 1997, Paris, France.

[27] Miyano Y, MacMurray MK, Enyama J, Nakada M. Loading rate and temperature dependence on flexural fatigue behavior of a satin woven CFRP laminate. J Compos Mater 1994; 28: 1250-60.

[28] Grassia L, D'Amore A, Simon SL. On the viscoelastic Poisson's ratio in amorphous polymers. J Rheol 2010; 54: 1009-22.

[29] Grassia L, D'Amore A. Constitutive law describing the phenomenology of subyield mechanically stimulated glasses. Phys Rev E Stat Nonlin Soft Mat Phys 2006; 74: 021504.

[30] Miyano Y, Nakada M, Kudok H, Muki R. Prediction of tensile fatigue of for unidirectional CRFP. J Compos Mater 2000; 34(7): 538-50.

[31] McCrum G, Bickley CP, Bucknall CB. In: Principles of polymer engineering. Oxford: Oxford University Press 1989.

[32] Chung I, Sun CT, Chang IY. Modeling creep in thermoplastic composites. J Compos Mater 1993; 27: 1009-29.

[33] Grassia L, D’Amore A. Isobaric PVT behavior of Poly(Carbonate) (PC). AIP Conf Proc 2010; 1255: 417-9.

[34] Grassia L, D'Amore A. Isobaric and isothermal glass transition of PMMA: Pressure-volume- temperature experiments and modelling predictions. J Non-Crystal Solids 2011; 357: 414-8.

[35] Grassia L, Pastore Carbone MG, Mensitieri G, D'Amore A. Modeling of density evolution of PLA under ultra-high pressure/temperature histories. Polymer 2011; 52: 4011-20.

[36] Yang Y, D'Amore A, Di Y, Nicolais L, Li B. Effect of physical aging on phenolphthalein polyethersulfone/poly(phenylene sulfide) blend. I. Mechanical properties. J Appl Polymer Sci, 1996; 59: $1159-66$

[37] Yang JN, Liu MD. Residual strength degradation model and theory of periodic proof tests for graphite/epoxy laminates. J Compos Mater 1977; 11: 176-203.

[38] Yang JN. Effect of high load on statistical fatigue of unnoched graphite/epoxy laminates. J Compos Mater 1980; 14: 82-94.

Received: September 21, 2012

Revised: November 03, 2012

Accepted: November 13, 2012

(c) Pasquale Verde; Licensee Bentham Open.

This is an open access article licensed under the terms of the Creative Commons Attribution Non-Commercial License (http://creativecommons.org/licenses/ by-nc/3.0/) which permits unrestricted, non-commercial use, distribution and reproduction in any medium, provided the work is properly cited. 